\title{
Quantitative Association Tests of Immune Responses to Antigens of Mycobacterium Tuberculosis: A Study of Twins in West Africa
}

\author{
Amanda Wiart, ${ }^{1,4}$ Annette Jepson, ${ }^{1 *}$ Winston Banya, ${ }^{3}$ Steve Bennett, ${ }^{2+}$ Hilton Whittle, ${ }^{2,3}$ Nicholas G. Martin, ${ }^{4}$ \\ and Adrian V. S. Hill' \\ 'Wellcome Trust Centre for Human Genetics, University of Oxford, United Kingdom \\ ${ }^{2}$ MRC Tropical Epidemiology Group, London School of Hygiene and Tropical Medicine, United Kingdom \\ ${ }^{3}$ Medical Research Council Laboratories, Fajara, The Gambia \\ ${ }^{4}$ Queensland Institute of Medical Research, Brisbane, Australia \\ *Current address: Department Clinical Microbiology, St. Mary's Hospital, London, United Kingdom \\ ${ }^{\dagger}$ We report with great sadness that Professor Bennett died in early 2003
}

\begin{abstract}
T here is now considerable evidence that host genetic factors are important in determining the outcome of infection with Mycobacterium tuberculosis (MTB). The aim of this study was to assess the role of several candidate genes in the variation observed in the immune responses to MTB antigens. In-vitro assays of T-cell proliferation, an in-vivo intradermal delayed hypersensitivity response; cytokine and antibody secretions to several mycobacterial peptide antigens were assessed in healthy, but exposed, West African twins. Candidate gene polymorphisms were typed in the NRAMP1, Vitamin D receptor, IL 10, IL4, IL4 receptor and CTLA-4 genes. Variants of the loci IL10 (-1082 G/A), CTLA-4 (49 A/G) and the IL4 receptor (128 A/G) showed significant associations with immune responses to several antigens. T-cell proliferative responses and antibody responses were reduced, TNF- $\alpha$ responses were increased for subjects with the CTLA-4 G allele. The T-cell proliferative responses of subjects with IL10 GA and GG genotypes differed significantly. IL4 receptor $A G$ and $G G$ genotypes also showed significant differences in their T-cell proliferative responses to MTB antigens. These results yield a greater understanding of the genetic mechanisms that underlie the immune responses in tuberculosis and have implications for the design of therapeutic interventions.
\end{abstract}

Tuberculosis is one of the world's foremost causes of death from a single infectious agent. The World Health Organization declared tuberculosis a global health emergency in 1993 and estimated that 2-3 million people die each year because of tuberculosis, with $95 \%$ of these deaths occurring in developing countries (Raviglione et al., 1995). The burden of tuberculosis in developing countries is compounded by risk factors such as concurrent HIV disease and the rise in prevalence of multidrug resistant strains of Mycobacterium tuberculosis (MTB).

Only $10 \%$ of individuals infected with MTB will develop disease (Murray et al., 1990). In these individuals, the protective immune response appears to be inadequate to combat clinical disease. The wide range of clinical manifestations of tuberculous disease may reflect the diversity of human immune defenses against MTB. The pathology of disease appears largely attributable to the nature of the host immune reactions. The immune response to MTB is thought to consist of both delayed-type hypersensitivity inflammatory mechanisms and a cell-mediated protective $\mathrm{T}_{\mathrm{H}} 1$ response. Kaplan and Freedman (1996) suggest that the balance between the inflammatory response and the protective T-cell response determines whether patients develop active disease.

The only vaccine currently available, Bacillus Calmette-Guérin (BCG), has a protective efficacy against pulmonary tuberculosis varying from nil to $80 \%$, possibly due to regional differences in exposure to environmental mycobacteria (Fine, 1995). Other possible causes include attenuation of the BCG vaccine (Behr et al., 1999) and genetic differences in host populations.

The components of the immune response to MTB are directed against a large and varied number of antigens that are presented by the bacilli during infection. Furthermore, there is evidence that disease progression

Received 26 August, 2004; accepted 10 September, 2004.

Address for correspondence: Adrian Hill, Wellcome Trust Centre for Human Genetics, University of Oxford, Roosevelt Drive, Oxford, OX3 7BN,UK.E-mail: adrian.hill@well.ox.ac.uk 
correlates with distinct immune profiles to defined antigens presented at different stages of the disease (Orme et al., 1993). So as to capture some of this complexity, we examined the in-vitro immune responses to a wide selection of antigens. The heat shock proteins hsp70 or $70 \mathrm{kD}$, hsp65 or $65 \mathrm{kD}$ (Young et al., 1987), and hsp10 or $10 \mathrm{kD}$ (Mehra et al., 1992) are among the most prominent of the antigenic proteins recognized by humans. Short-term culture filtrate (STCF) is highly enriched in proteins actively secreted by the bacterium that are important targets for the immune system. The antigens identified in this filtrate include $10 \mathrm{kD}$ hsp, antigen 85 complex $(\mathrm{Ag} 85)$ and ESAT6. ESAT6 is a dominant target in the early phase of infection. Antigenic peptides (EG602, EG603) derived from ESAT6 were used in this study.

The $38 \mathrm{kD}$ antigen has been shown to induce the most frequent and highest titres of serum antibodies in tuberculosis (Jackett et al., 1988). Peptides derived from this antigen were used to stimulate T-cell proliferation. Purified protein derivative (PPD) is a crude antigenic mixture prepared from heat-killed MTB cultures, that is widely used to evaluate the immunological response of individuals; two preparations were used in this study, RT48 (Statens Serums Institute, Copenhagen) and PPD supplied by Evans Medical, Horsham, UK (hereafter called 'Evans'). Among the prominent molecules of the mycobacterial cell envelope is the complex lipoglycan, lipoarabinomannan (LAM): this is a potent stimulus for TNF- $\alpha$ release from macrophages. In general, mannose-capped LAM (ManLAM) is associated with the slow-growing species of mycobacteria, while the arabinosylated form (AraLAM) predominates in the fast-growing; AraLAM uses the lipopolysaccharide (LPS gram negative cell wall endotoxin) receptor CD14 to enter the macrophage, whereas ManLAM also uses the mannose receptor (Schlesinger, 1993). Differential receptor interaction may influence subsequent intracellular signaling and consequent immune response.

The clustering of tuberculosis within families has been reported many times; several studies have demonstrated that siblings of tuberculosis patients were more at risk of dying from tuberculosis than marital partners (Pearson, 1907; Puffer, 1946). Twin studies have provided convincing evidence for the role of host genetic factors for different infectious diseases (Hill, 1998). Our previous work demonstrated that invitro immune responses to defined mycobacterial proteins and peptides were also subject to genetic regulation (Jepson et al., 2001). The question is no longer whether there is a genetic component in the susceptibility to tuberculosis but how, by what mechanism, and to what degree genetic factors determine the response to exposure or disease.

Several studies have now been undertaken to elucidate the key immune response genes that may be involved in susceptibility to tuberculosis. There is substantial evidence for the importance of non-MHC genes in diseases such as malaria (Jepson et al., 1997), autoimmune diseases (reviewed by Wandstrat $\&$ Wakeland, 2001) and tuberculosis. Bellamy et al. (1998a, 1998b) first showed that tuberculosis is associated with variation in the NRAMP1 and Vitamin D receptor genes. The aim of the present study was to identify the genes that may be involved in the regulation of the immune responses to tuberculosis antigens (Jepson et al., 2001). Despite numerous candidate studies of genetic susceptibility to tuberculosis almost nothing is known about specific non-HLA genes that may influence immune responses to mycobacterial antigens in humans. We have recently shown in Gambian twins that several such immune responses show substantial heritability and that most of the genetic component may lie outside the major histocompatibility complex (Jepson et al., 1997, 2001). In particular, it was demonstrated that memory T-cell responses to secreted mycobacterial antigens (antigen 85 complex, STCF and peptides from the ESAT6), as well as to the $65 \mathrm{kD}$ heat shock protein, are subject to effective genetic regulation. The delayed hypersensitivity response to intradermal tuberculin also demonstrated significant genetic variance (Jepson et al., 2001).

The selection strategy for the candidate genes was based first on their functional importance in the immunological responses occurring during infection with MTB, and second on whether there was accumulating evidence for association with other bacterial and autoimmune diseases. CTLA- 4 is a member of the CD28 receptor family; the counterreceptors for these proteins are the B-7 family members, B7-1 and B7-2 expressed on antigen presenting cells. The B7: CD28/CTLA-4 pathway is important in antigen specific T-cell activation, since T-cell activation in the absence of co-stimulation results in development of anergy or cell death (Schwartz, 1990). The pathway may also play an important role in influencing T-cell differentiation (Battifora et al., 1998; Greenfield et al., 1998). This has been an important area of study for the $\mathrm{T}_{\mathrm{H}} 2$ cell-mediated allergic responses and atopic diseases. In mice, the B7-CD28/CTLA-4 co-stimulatory pathways are required for the development of $\mathrm{T}_{\mathrm{H}} 2$ mediated allergic airway responses (Keane-Myers et al., 1997). There have been several studies showing evidence for an association between CTLA- 4 and autoimmune diseases. These include associations between CTLA-4 and Graves diseases (Ueda et al., 2003; Yanagawa et al., 1997), Hashimoto's thyroiditis (Donner et al., 1997), diabetes (Ueda et al., 2003) and rheumatoid arthritis in Spanish patients (GonzalezEscribano et al., 1999; Seidl et al., 1998).

IL10 plays a critical role in immune regulation by controlling the balance between an inflammatory and a humoral response. It has stimulatory effects on Bcells, but an inhibitory effect on macrophages and $\mathrm{T}_{\mathrm{H}} 1$ cells. IL10 may play a role in suppressing IFN- $\gamma$ production and concurrent $\mathrm{T}_{\mathrm{H}} 1$ cell response in tuber- 
culosis (Gong et al., 1996). Furthermore, differential expression of IL10 has been implicated in a number of autoimmune diseases (Rousset et al., 1992). There are several polymorphisms of single-base substitutions at positions, $-1082,-819$ and -592 in the promoter region (Eskdale at el. 1998; Turner et al., 1997). The mutation at position -1082 from $G$ (high responder) to A (low responder) results in a twofold decrease in the production of IL10 (Turner et al., 1997).

IL4 operates through the bipartite IL4 receptor; the two subunits of IL4R mediate ligand endocytosis in IL4 responsive cells (Lischke et al., 1998). IL4R is found on B and T-cells, macrophages and mast cells. The importance of IL4 and its receptor in polarizing the T-cell response to a $T_{H} 2$ immune response indicates that it is a plausible candidate for immune responses in tuberculosis, where a $\mathrm{T}_{\mathrm{H}} 2$ response leads to exacerbation of disease. The effects of specific variants of genes encoding the vitamin D receptor, IL4 and NRAMP1 were also tested for these immune responses.

\section{Subjects and Methods}

Recruitment for this study was conducted in The Gambia, West Africa between January 1996 and April 1997. Two hundred and eighty-two twin pairs aged 12 to 85 years agreed to participate in the study: all were living in rural villages within four hours drive of one of the three Medical Research Council (MRC) field stations. At the time of blood collection, subjects were also tested for mycobacterial exposure with a tuberculin skin test. The study protocol was approved by the Gambia Government/MRC Ethics Committee, and further details can be found in Jepson et al. (2001).

Several in-vitro immune assays were conducted to test the wide range of immune responses that might occur in response to invading bacilli. T-cell proliferative responses to several antigens and antigenic peptides were measured using $\mathrm{H}$-thymidine incorporation (Jepson et al., 2001). A whole blood assay was used to measure TNF- $\alpha$ responses following stimulation by ManLAM and AraLAM. An enzyme-immunoassay method using a highly specific recombinant $38 \mathrm{kD}$ antigen from the MTB was used to detect $\operatorname{IgG}$ antibodies in human serum (Jepson et al., 2001). DNA was extracted from the remaining blood cells using Nucleon II kits as per manufacturer's instructions (Scotlab UK). Zygosity of all twin pairs was determined by typing at least seven independent highly polymorphic microsatellite markers. The genotypes for each of the candidate genes were determined by means of PCR and allele-specific oligonucleotide hybridization.

Frequency distributions for each of the measured in-vitro immune responses were assessed by normal probability plots. T-cell proliferative stimulation indices and $\operatorname{IgG}$ responses were log-transformed; a square root transformation was applied to the TNF- $\alpha$ response $(\mathrm{pg} / \mathrm{ml})$. All references to the immune responses are to their transformed values.

We fitted a twin path model using Mx (Neale, 1997) to estimate the proportion of variation in T-cell proliferative responses, antibody response and TNF- $\alpha$ production explained by genetic factors. For each immune response, a baseline model was fitted which allowed for additive genetic (A), nonshared environment (E), and either dominant genetic (D) or shared environmental (C) sources of variation. Results from these models have been published previously (Jepson et al., 2001). In these models, maximum likelihood analyses of individual observations are used to test simultaneously hypotheses about the means, variances and covariances (Martin et al., 1987). This provides a way of allowing for the effects of covariates, such as sex and age while simultaneously estimating genetic and environmental variance effects (Dolan et al., 1989; Neale \& Martin, 1989). Since association analysis involves looking at mean differences in phenotypes between groups with different marker alleles; it is possible to test the contribution of these polymorphisms to the total genetic variance by including the candidate polymorphisms as covariates in the model as is done for age or sex (Whitfield et al., 2000). An analysis of association then tests the significance of the quantitative trait locus by removing it from the model, while the residual genetic and environmental variance parameters are allowed to vary. The fit of each submodel, in which the quantitative trait locus is removed is assessed by twice the difference in log likelihood between the full and submodels (MacGregor et al., 1999). This difference is distributed as $\chi^{2}$ with degrees of freedom $(d f)$ equal to the difference in $d f$ between the models.

First, association analysis was carried out under the assumption of additive effects for each of the candidates (allelic model). Further models were tested that allow for the possibility of dominance where the phenotypic value of the heterozygote may be closer to one homozygote than the other. The four models tested were:

Model 1: Allows for an additive allelic effect; for example, for CTLA4 the effect of having two G alleles would be twice as great as that of having one $G$ allele.

Model 2: Allows for the possibility of dominance; for example, for CTLA4 this tests the dominance of the A allele by constraining AG and AA to be equal and different from GG.

Model 3: Allows for the possibility of dominance in the opposite direction; for example, for CTLA4 this tests the dominance of the $G$ allele by constraining $A G$ and $G G$ to be equal and different from AA.

Model 4: Allows for the possibility of partial dominance by estimating unconstrained deviations for two genotypes from the baseline value of the third genotype. This is the most general model with $2 d f$; models 1-3 differ from it by a single $d f$. 
These models were fitted to all variables, including those that had not shown significant heritability in the initial variance components analysis, as this may be due to the lack of power associated with the small number of twins. Only variables for which there was some evidence for association are shown here. Results for fitting model 4 to the data are not shown here because it did not result in improved model fit for any of the antigens.

Mean differences in phenotype as a function of allelic effect could occur from either functional effects of the locus itself, or from linkage disequilibrium with a nearby functional site, or association could be spurious arising from population stratification (Neale et al., 1999). It is possible to test whether the association is genuine by fitting models in which the association effect is split into a within twin pair-additive deviation, $a w$ and a between-pair component, $a b$. If $a w$ is not significantly different from zero, or if $a b$ is significantly greater than $a w$, this suggests that stratification may be present (Fulker et al., 1999). Sham et al. (2000) have extended this to include between- and within-pair dominance deviations. However, only DZ twin pairs that have either the recessive or dominant genotypes are informative for this test, and for the few variables that showed dominance effects in our study there were too few such pairs. Finally, sources of covariation between the immune response phenotypes were tested in a multivariate model to take advantage of increased power to detect association.

\section{$\overline{\text { Results }}$ \\ Genotyping}

The cohort comprised $62 \mathrm{MZ}$ twin pairs and $188 \mathrm{DZ}$ twin pairs. There were 30 pairs of $M Z$ females (MZF), 32 pairs of MZ males (MZM), 78 pairs of DZ females (DZF), 46 pairs of DZ males (DZM) and 64 pairs of opposite sex pairs (DZO). The mean age for the MZ twins was 24.361 .1 years, and for DZ twins it was 25.260 .72 .

The allele frequencies at each locus (Table 1) were estimated by taking only one subject from each twin pair randomly. The allele frequencies for NRAMP1, vitamin D receptor, IL4 and IL10 are similar to those found in a previous association study of susceptibility to tuberculosis in The Gambia (Bellamy, 1998). The genotype frequencies did not deviate significantly from those expected under Hardy-Weinberg equilibrium.

\section{CTLA-4}

The CTLA-4 exon 1 codon 17 dimorphism (49A/G) corresponding to the amino acid change threonine to alanine was typed. The effects of the $\mathrm{A} 49 \mathrm{G}$ polymorphism were tested under the assumption of additive effects (i.e., that the effect of two G alleles would be twice as great as that of one allele). The effect of the polymorphism on the measured immune responses was assessed by comparing the most parsimonious

\section{Table 1}

Candidate Gene Allelic Frequencies

\begin{tabular}{lcc}
\hline Locus & Allele & Frequency $(S E)$ \\
\hline CTLA4 & $\mathrm{A}$ & 0.6660 .02 \\
VDR & $\mathrm{T}$ & 0.7160 .021 \\
NRAMP & $+\mathrm{tgtg}$ & 0.8060 .018 \\
IL10 & $\mathrm{G}$ & 0.3560 .024 \\
IL4 & $\mathrm{C}$ & 0.3160 .022 \\
IL4R & $\mathrm{A}$ & 0.5160 .025 \\
\hline
\end{tabular}

Note: $R=$ receptor. VDR = vitamin $D$ receptor. $I L=$ interleukin. Biallelic nucleotide variants are referred to by the nucleotide substitution in question. The alleles for the Vitamin D receptor RFLP are denoted as $\mathrm{T}=$ absence of the Taql Site and $\mathrm{t}=$ presence of the site. NRAMP1 base pair deletion is denoted by ' $+\mathrm{tgtg}$ ' and

'- - gtg' for the insertion and deletion alleles respectively

model with means adjusted for allelic effect with the reduced model in which the allelic effect was removed from the model. Dropping the allelic deviation for the $G$ allele from the models resulted in a worsening of model fit for each of the antigens (Table 2 ). The additive genetic variance decreases for all the variables when the allelic deviation is in the model, which is further evidence of an association (Fulker et al., 1999). Addition of the allelic effect significantly improved the fit of the model for IgG, even though the estimate of the additive genetic variance was not significant. However, there is greater power to detect genetic mean effects than genetic variance components in these models.

The results of the Fulker test, which is used to assess population stratification as a possible cause of association, are presented in Table 3. This modeling procedure only makes use of DZ pairs and since the number of subjects is consequently reduced, the analysis will have less power to detect allelic effects than in the full model. Nevertheless, the associations were confirmed as resulting from allelic effects rather than population stratification for all except the antigen ManLAM. The association previously identified between ManLAM and CTLA- 4 is not confirmed by the Fulker test, since dropping the within-pair component does not lead to worsening of model fit. This might be attributable to the reduction in sample size and consequent loss of power. The within- and between-pair parameters cannot be equated for STCF, therefore the estimates of association may be influenced to some extent by population substructure. However, there is a large within-family effect, suggesting that the association is genuine.

\section{Interleukin 4 receptor (IL4R)}

An IL4 receptor polymorphism that leads to an amino acid change from isoleucine $(A)$ to valine $(G)$ was typed; it is located in the extracellular domain of the receptor and is 148 base pairs from the start codon (Deichmann et al., 1997). Only STCF showed somewhat significant association under the assump- 
Table 2

Association Analysis of the CTLA-4 Locus With Immune Responses to Tuberculosis Antigens Using an Additive Model (Model 1)

Shown are the proportions of additive variance $\left(a^{2}\right)$ for each of the means models, which include a deviation for the $\mathrm{G}$ allele of the A49G polymorphism and the same proportion when the allelic deviation is dropped (second model, $a^{2}$ ). The percentage of genetic variance explained by the $G$ allele can be estimated from the difference between the $a^{2}$ for the full model and $a^{2}$ from the reduced model.

$\Delta \chi^{2}$ is the worsening of fit for the second model compared to the first. The deviation for the $\mathrm{G}$ allele is in standard units and its $95 \%$ confidence interval is included.

\begin{tabular}{|c|c|c|c|c|c|}
\hline & Cell proliferation & Cell proliferation & Cell proliferation & Antibody & TNF \\
\hline Parameters & Evans & STCF & $38 \mathrm{G} 01$ & $\lg G$ & ManLAM \\
\hline$a^{2}$ & 0.24 & 0.46 & 0.06 & 0.00 & 0.43 \\
\hline$a^{2^{\prime}}$ & 0.31 & 0.48 & 0.07 & 0.00 & $0.48^{*}$ \\
\hline$\Delta \chi^{2 \mathrm{~b}}$ & $4.69^{*}$ & $5.44^{*}$ & $7.13^{* *}$ & $4.59^{*}$ & $4.63^{*}$ \\
\hline Allelic deviation & -0.31 & -0.25 & -0.13 & -0.66 & 0.41 \\
\hline $95 \% \mathrm{Cl}$ & -0.59 to -0.03 & -0.47 to -0.05 & -0.22 to -0.03 & -0.13 to -0.01 & 0.03 to 0.79 \\
\hline
\end{tabular}

Note: 'Evans' (a purified protein derivative mixture), 38G01 (a peptide derived from the 38kD antigen), and STCF were used to stimulate proliferative responses. IgG levels were measured in response to stimulation by 38kD. ManLAM was used to stimulate a TNF response. The models also allow for sex, area, ethnicity and age.

$a^{2}$ is variance of additive genetic effects, ${ }^{*}<.05,{ }^{* *}<.01 ; \mathrm{df}=1$ for Model 1

tion of additivity $\left(\Delta \chi^{2}=4.38, p<.05\right)$ but this was not confirmed by the within-pairs test $\left(\Delta \chi^{2}{ }_{1}=1.35, p\right.$ $=.25)$. However, a genotypic model specifying dominance of the $G$ allele in the increasing direction was found to be significant for $65 \mathrm{kD}$, STCF and RT 48 (Table 4). For the EG602 antigen the dominance is significant for the A allele in the decreasing direction (Table 4).

\section{Interleukin 10 (IL10)}

There are many known polymorphisms in the IL10 gene; three of these $(-1082,-819$ and -592$)$ in the promoter region are in strong linkage disequilibrium (Bellamy \& Hill, 1998a). The 1082 (G/A) polymorphism was typed in this study, since there is some evidence of it being functional (Turner et al., 1997). The effect of the IL10 polymorphism was tested first under the assumption of additivity by adding a deviation for the $G$ allele to the models adjusted for covariates. Further models that allowed for the possibility of dominance were also examined.

Eliminating the effects of the IL10 G allele for the PPD reagent RT48 produced a significant worsening of model fit, indicating that the IL10 locus may account for a proportion $(1 \%)$ of the genetic variance in memory T-cell response to this antigen (Table 5). This was marginally confirmed by the Fulker test; setting $a w=0$ produced $\Delta \chi^{2}{ }_{1}=3.47,(p=0.06)$, the within-family and between-family parameters could also be equated, which suggests that the association is not entirely due to population stratification.

The log likelihood $\chi^{2}$ difference between the models for the ESAT6 peptide (EG602) indicate that there was no significant allelic effect $\left(\chi^{2}{ }_{1}=0.23\right)$ implying that the assumption of additivity does not apply in this case. Fitting genotypic models to these same data suggested dominance of the $G$ allele in the decreasing direction, but the fact that the model specifying this fixed effect has a greater residual variance $\left(a^{2}=0.43\right)$ than the model without this deviation $\left(a^{2}\right)$ $=0.36)$ makes this result suspect (Table 5).

\section{Other Candidate Genes}

The polymorphism typed in the IL4 gene is the IL4 -590 promoter, which is a $\mathrm{C}$ to $\mathrm{T}$ transition (Rosenwasser et al., 1995). There was no evidence of any association of IL4 with the immune assays measured in this study. There was also no evidence of an association of the $4 \mathrm{bp}$ 'TGTG' insertion/deletion polymorphism in the 3' UTR of NRAMP1 with any of the immune responses to the tuberculosis antigens. Results from modeling an effect of the vitamin D receptor polymorphism $\mathrm{T} / \mathrm{t}$ variant on the proliferative responses and the TNF- $\alpha$ responses presented no evidence of an association with this polymorphism in this study of Gambian twins. There was also no evidence of any significant effect of the candidate genes on the delayed hypersensitivity skin response.

\section{Table 3}

Fulker Tests for the Within-Pair Association Between the CTLA-4 A49G Polymorphism and Proliferative Responses in DZ Twin Pairs Only

Tabled are the likelihood ratio chi-squares for dropping aw (Model 1) or equating $a w=a b$ (Model 2).

\begin{tabular}{lcc}
\hline & Model 1 & Model 2 \\
\hline Drop aw & aw =ab \\
\hline Evans & $6.425^{*}$ & 1.919 \\
STCF & $8.855^{* *}$ & $4.582^{*}$ \\
$38 G 01$ & $3.836^{*}$ & 0.605 \\
IgG & $3.931^{*}$ & 0.412 \\
ManLAM & 1.341 & 0.485 \\
\hline
\end{tabular}

Note: Allelic deviations are partitioned into those occurring between and within sibpairs. In Model 1, the within-pair component is set to 0 , and a significant aw indicates that the association is genuine. In Model 2, if the parameters are not equal the association may be due in part to population stratification.

${ }^{*} p<.05,{ }^{* *} p<.01 ; \mathrm{df}=1$ for both Model 1 and Model 2 
Table 4

Tests for the Effects of the IL4 Receptor Polymorphism on Proliferative Responses Using Dominant Models

Shown are the proportions of variance $\left(a^{2}\right)$ for models 2 and 3 , which include deviations for the $A G$ and $A A$ genotypes. $a^{a^{2}}$ is the proportion of variance when either $A G$ is constrained to equal $G G$ (model 2) or $A G$ is constrained equal to $A A$ (model 3 ). $\Delta \chi^{2}$ is the worsening of fit for the submodel as compared to full model with genotypes unconstrained. Deviations from the baseline genotype $G G$ are shown for both the heterozygote $A G$ and homozygote AA. Deviations are in standard units with $95 \%$ confidence intervals.

\begin{tabular}{|c|c|c|c|c|c|}
\hline & Parameters & RT48 & STCF & $65 \mathrm{kD}$ & EG602 \\
\hline \multicolumn{6}{|l|}{ Model 2} \\
\hline \multirow[t]{5}{*}{ G dominant } & $a^{2}$ & 0.04 & 0.46 & 0.29 & 0.48 \\
\hline & $a^{2^{\prime}}$ & 0.09 & 0.48 & 0.31 & 0.48 \\
\hline & $\Delta \chi^{2}$ & $4.08^{*}$ & $5.78^{*}$ & $4.45^{*}$ & 0.51 \\
\hline & Genotype deviation AG & -0.34 & -0.44 & -0.26 & 0.07 \\
\hline & $95 \% \mathrm{Cl}$ & -0.67 to -0.01 & -0.82 to -0.08 & -0.50 to -0.02 & -0.11 to 0.24 \\
\hline \multicolumn{6}{|l|}{ Model 3} \\
\hline \multirow[t]{5}{*}{ A dominant } & $a^{2}$ & & & & 0.48 \\
\hline & $a^{2^{\prime}}$ & & & & 0.52 \\
\hline & $\Delta \chi^{2}$ & & & & $5.3^{*}$ \\
\hline & Genotype deviation AA & & & & -0.12 \\
\hline & $95 \% \mathrm{Cl}$ & & & & -0.31 to 0.09 \\
\hline
\end{tabular}

Note: RT48 (a purified protein derivative mixture), 65kD (a heat shock protein), EG602 (peptide derived from the ESAT6 antigen) and STCF were used to stimulate proliferative responses.

${ }^{*} p<.05,{ }^{* *} p<.01$

\section{Covariation Analysis Between the Proliferative Responses to MTB Antigens}

There were highly significant correlations between the proliferative responses to many of the antigens analyzed (Jepson et al., 2001) and this covariation can increase the power of association analyses. Multivariate Cholesky decomposition (Neale \& Cardon, 1992) was used as a means of examining the effects of the polymorphisms on these correlations. The allelic effects of CTLA4 in a Cholesky decomposition model for RT48, 'Evans', Antigen 85 complex and STCF were examined. Dropping the CTLA4 covariate from the model separately for each of the antigens resulted in a significant worsening of model fit for RT48 $\left(\Delta \chi^{2}{ }_{1}=4.043, p=.04\right)$, 'Evans' $\left(\Delta \chi^{2}{ }_{1}=\right.$ 7.034, $p=.008)$ and STCF $\left(\Delta \chi^{2}{ }_{1}=8.058, p=.005\right)$.

To determine the effect of the IL4 receptor polymorphism in a multivariate model, a Cholesky decomposition was fitted which allowed for the possibility of dominance effects on the means. This confirmed the dominance effects of the GG homozygote seen in Table 4 , but with increased significance on RT48 $\left(\Delta \chi^{2}{ }_{1}=4.36, p=.03\right)$, and STCF $\left(\Delta \chi^{2}{ }_{1}=\right.$ 7.72, $p=.005)$.

\section{$\overline{\text { Discussion }}$}

There was a negative association of the CTLA-4 allelic variant $(G)$ with the magnitude of proliferative responses to the $38 \mathrm{G} 01$ peptide, 'Evans' and STCF; levels of $\mathrm{IgG}$ secreted in response to the $38 \mathrm{kD}$ antigen were also reduced for this variant. There was a marginal effect of homozygosity for peptides $8 \mathrm{~T}$ and EG602; G/G individuals had lower proliferative responses than did either AA or AG subjects suggesting dominance of the $A$ allele in the increasing direction. Interestingly, levels of TNF- $\alpha$ secreted to ManLAM were significantly higher in those with the $G$ variant. Proliferative responses are decreased and TNF response increased for those individuals with the $\mathrm{G}$ allele. The Fulker tests confirmed that the CTLA-4 polymorphism appears to have a genuine effect on the immune responses to these antigens, except for ManLAM. The most important of the co-stimulatory pathways required for T-cell activation is the B7: CD28/CTLA-4 pathway, which can stimulate both $\mathrm{T}_{\mathrm{H}} 1$ and $\mathrm{T}_{\mathrm{H}} 2$ type cells. CTLA- 4 is expressed only on activated cells and, since it can transduce an inhibitory signal, its function may be to terminate Tcell activation (Walunas et al., 1994). Co-stimulatory molecules are thought to play a role in the pathogenesis of infectious diseases, as there is evidence that microbial products can affect their expression (Liu \& Janeway, 1991; Saha et al., 1998).

The effects of CTLA-4 on T-cell differentiation to polarized T-cell subsets is incompletely defined and may be distinct for the disease model investigated. For example, inhibition of the effect of CTLA-4 has been shown to enhance both the $\mathrm{T}_{\mathrm{H}} 1$ immune response in a mouse model of BCG infection and in some autoimmunity models, but also the $\mathrm{T}_{\mathrm{H}} 2$ response in a model of leishmaniasis (Heinzel \& Maier, 1999; Kirman et al., 1999). These findings suggest that CTLA-4 nonselectively modulates T-cell phenotypes formerly biased by independent events. Reiser and Stadecker (1996) suggest that the importance of this co-stimulatory pathway may be in its role in influencing T-cell differ- 
entiation into $T_{H} 1$ and $T_{H} 2$ cells. Very few functional studies of the CTLA-4 polymorphisms have been carried out. A preliminary study indicated a correlation between the exon $1(\mathrm{~A} / \mathrm{G})$ SNP (typed here) and CTLA4 mRNA levels in PBMC, but this has not been replicated (reviewed by Kristiansen et al., 2000). The association described between the CTLA-4 exon 1 ' $G$ ' allele and reduced in-vitro proliferative responses may, therefore, be due to linkage disequilibrium with a nearby gene or a functional variant. Further functional studies of the polymorphism typed in this study are required. In addition it would be of interest to assess associations of the immunological phenotypes studied with the more recently described polymorphisms in the 3' noncoding region of CTLA-4. Such variants appear to be functionally significant and have been associated with several autoimmune diseases including type I diabetes and Grave's disease (Ueda et al., 2003).

The development of naive T-cells into differentiated $\mathrm{T}_{\mathrm{H}} 2$ cells is dependent on presence of IL4 in the cytokine environment, itself a $T_{H} 2$ cytokine, but might also depend on the nature of the antigenic stimulation (O'Garra, 1998); co-stimulatory signals such as those delivered by CD28 may be important too. In fact, CD28 has been shown to enhance the sensitivity of naive T-cells to IL4 by altering the IL4 receptor signaling cascade, thus accelerating differentiation of naive T-cells into $\mathrm{T}_{\mathrm{H}} 2$ cells (Kubo et al., 1999). This provides some evidence that the IL4 receptor may be important in T-cell differentiation. There is also evidence that $\mathrm{T}_{\mathrm{H}} 2$ cytokines, such as IL4 may be involved in the downregulation of the $\mathrm{T}_{\mathrm{H}} 1$ response in tuberculosis (Schluger et al., 1999; Surcel et al., 1994). The effects of IL4 are mediated by interactions with its receptor.

IL4 plays a central role in the immunopathogenesis of allergic diseases, and the expression of IL4 receptor on the surface of lymphocytes is increased in certain allergic and autoimmune diseases (Mozo et al., 1998). Data from both mouse and human cell lines provide some evidence of a functional effect for the polymorphism typed in this study. The Ile50 (Isoleucine variant which corresponds to substitution of allele $\mathrm{A}$ in the DNA sequence) variant of the receptor was shown to significantly upregulate receptor response to IL4 with resultant increased activation and increased production of $\operatorname{IgE}\left(\mathrm{T}_{\mathrm{H}} 2\right.$ response; Mitsuyasu et al., 1999). A recent study showed no evidence of an association of this polymorphism with tuberculosis disease per se in West Africans (Cervino et al., 2000).

In this Gambian twin cohort, the most prominent effect of the IL4 receptor genotype (Ile50Val an A to G substitution) was the major effect of homozygosity of the A50G allele. Individuals with G/G genotypes had much higher proliferative response to RT48, 65kD hsp and STCF than either A/G or A/A subjects. This large effect of the second $G$ allele shows the quantitative dominance of the A allele in the increasing direction. These findings indicate that individuals with $\mathrm{A} / \mathrm{A}$ genotypes that are thought to have an increased $\mathrm{T}_{\mathrm{H}} 2$

Table 5

Tests for the Effects of the IL10 Polymorphism on Stimulation Indices to RT48 and EG602

Shown are the proportions of variance $\left(a^{2}\right)$ for the additive and dominance models. The additive model includes a deviation for the $\mathrm{G}$ allele; the dominance models include a deviation for the $A G$ and $G G$ genotypes. $a^{2}$ is the proportion of variance when either $A G$ is constrained to equal $A A$ (model 2) or AG is constrained equal to GG (model 3). $\Delta \chi^{2}$ is the worsening of fit for submodel as compared to the full model with allelic or genotype effects left unconstrained. Deviations from the baseline genotype AA are shown for both the heterozygote AG and homozygote GG. The deviations are in standard units with $95 \%$ confidence intervals.

\begin{tabular}{cccc}
\hline Model & Parameters & RT48 & EG602 \\
\hline Additive & $a^{2}$ & 0.00 & 0.42 \\
& $a^{2^{2}}$ & 0.01 & 0.39 \\
& $\Delta \chi^{2}$ & $6.72^{* *}$ & 0.23 \\
& Allelic deviation & -0.26 & -0.02 \\
& Cl Mean & -0.46 to -0.06 & -0.12 to 0.08 \\
\hline A dominant & $a^{2}$ & 0.00 & 0.43 \\
& $a^{2}$ & 0.00 & 0.42 \\
& $\Delta \chi^{2}$ & 0.52 & 1.55 \\
G dominant & Genotype deviation AG & -0.11 & 0.09 \\
& Cl & -0.41 to 0.19 & -0.06 to 0.24 \\
\hline$a^{2}$ & 0.00 & 0.43 \\
& $a^{2}$ & 0.02 & 0.36 \\
& $\Delta \chi^{2}$ & $5.79^{*}$ & $4.09^{*}$
\end{tabular}

Note: RT48 (a purified protein derivative mixture) and EG602 (peptide derived from the ESAT6 antigen) were used to stimulate proliferative responses. ${ }^{*} p<.05,{ }^{* *} p<.01$ 
response may also have a decreased T-cell mediated immune response. RT48 and 'Evans' are both purified protein-derivative mixtures so the expectation is that these would have very similar association profiles. In fact, 'Evans' only approaches significance for association with IL4R and this might be due to the lower numbers of twins tested for their immunological response to 'Evans'. Indeed, proliferative responses to 'Evans' did show an association with this polymorphism in the more powerful multivariate analysis.

Unfortunately, tests for the confounding effects of population stratification for the dominance effect of the IL4 receptor were not possible because of the small number of informative DZ pairs. STCF and RT48 showed additive effects for this polymorphism too; these results were confirmed with the more stringent Fulker test.

It has been suggested that IL10 may play a role in tuberculosis by downregulating the $\mathrm{T}_{\mathrm{H}} 1$ response, specifically IFN $\gamma$ production and CTLA-4 expression (Gong et al., 1996). In fact, IL10-deficient mice have increased antimycobacterial immunity (Murray \& Young, 1999). The 'A' allele of the polymorphism typed in this study, in the promoter region at position -1082 , has been found to be associated with decreased IL10 production in patients with Crohn's disease and controls (Koss et al., 2000), providing evidence that this polymorphism has an effect on cytokine production.

The mutation at position -1082 from a $G$ (high responder) to an A (low responder) results in a twofold decrease in the production of IL10 (Turner et al., 1997). The -1082 polymorphism has been shown to be associated with several autoimmune diseases (reviewed by Bidwell et al., 1999). Subjects with GG genotypes (high responders) showed decreased proliferative response to RT48 and the ESAT6 peptide, EG602. These findings suggest that individuals with $\mathrm{G} / \mathrm{G}$ genotypes have increased levels of IL10 and decreased proliferative response to some mycobacterial antigens. The similarity of immune responses for subjects with $\mathrm{A} / \mathrm{A}$ and $\mathrm{A} / \mathrm{G}$ genotypes suggests the quantitative dominance of the ' $\mathrm{A}$ ' allele. It is possible to speculate that individuals with $\mathrm{G} / \mathrm{G}$ genotypes may have a decreased $\mathrm{T}_{\mathrm{H}} 1$ response that could lead to susceptibility to disease. However, Bellamy (1998) found no association with this polymorphism and disease susceptibility in The Gambia.

The importance of the $T_{H} 1 / T_{H} 2$ balance in determining the outcome of the host immune defense to invading bacilli has been highlighted. Therefore, polymorphisms in genes that affect the polarization of the immune response may have important implications for the outcome of the immune response. If it is biased toward a $\mathrm{T}_{\mathrm{H}} 1$ response, the response may be protective; however, a more pronounced $\mathrm{T}_{\mathrm{H}} 2$ response may lead to severe pathogenic response. In this regard, this study has demonstrated significant associations with IL4 receptor, IL10 and CTLA-4, which may all play a role in polarizing T-cell responses. Furthermore, there is additional evidence that other genes may influence immune response to tuberculosis, since each of the associations in this study only accounts for a small proportion of the genetic variance of each trait. There are, therefore, likely to be a number of genes with individually small and additive effects.

The hormonally active form of Vitamin D3 inhibits the ability of macrophages to induce T-cell differentiation through an as yet unknown mechanism. It has been shown that Vitamin D differentially regulates B7 expression on macrophages and that this might contribute to its inhibitory effect (Clavreul et al., 1998). Wilkinson et al. (2000) found that Vitamin D deficiency was associated with active tuberculosis and the combination of this deficiency with TT/Tt genotypes was associated with disease. Bellamy et al. (1999) found that subjects with tt genotypes were resistant to tuberculosis. Therefore, the evidence supporting Vitamin D receptor association with mycobacterial diseases is quite compelling. However, from this study there was little evidence of a role for this locus on $\mathrm{T}$ cell activation. The results from this study may in part be explained by recent findings indicating a role for vitamin D3 in maturation of antigen-presenting cells acting at the very first step of the immune response (Penna \& Adorini, 2000; Piemonti et al., 2000).

The aim of the present study was to assess the effects of several candidate polymorphisms on different immune responses to MTB antigens. This by necessity involved multiple tests; it is therefore difficult to infer in the case of individual variants whether the evidence for association is due to multiple comparisons and chance or a real biological effect. We did not make an adjustment for multiple testing because the purpose of the study was to test several immune-response associations and we believe that for this purpose it is more informative to report all the positive results. We recognize the issue of multiple testing and it has been taken into consideration in the interpretation of the results. Nevertheless there are several findings that support a real biological cause for the positive association results in the present study. Only CTLA-4, IL10 and IL4 receptor showed evidence of associations with many of the antigens. Furthermore, several antigens that are known to be of immunological significance in tuberculosis showed associations with each of the candidates. The increase in power arising from the multivariate analysis further supported some of the trends observed in the univariate analysis. There is some evidence in the literature that almost all the polymorphisms typed in this study may have functional effects, but in each case further functional studies are required. The results encourage further investigation of the associations of the defined CTLA-4, IL4 receptor and the IL10 polymorphisms and immune responses to a variety of mycobacterial and other antigens.

Identification of host genes involved in immune responses to mycobacterial antigens should assist in 
gaining a better understanding of the pathogenesis of disease and ultimately to new therapeutic strategies. Indeed, modulation of the host response in the fight against mycobacteria may be at the forefront of these strategies. It is likely that for a multifactorial disease, such as tuberculosis, a concurrence of diverse genetic and nongenetic factors are needed in order to reach a threshold level for disease.

\section{Acknowledgments}

This study was supported by a Wellcome Trust career development fellowship grant to A. J. A. W. is especially grateful to David Evans, Gu Zhu and David Duffy for their assistance with the statistical analysis and for useful discussions. AVSH is a Wellcome Trust principal research fellow. We thank those who provided antigens for the study. Above all, we would like to thank the twins and their families in The Gambia for taking part in this study.

\section{References}

Battifora, M., Pesce, G., Paolieri, F., Fiorino, N., Giordano, C., Riccio, A. M., Torre, G., Olive, D., \& Bagnasco, M. (1998). B7.1 costimulatory molecule is expressed on thyroid follicular cells in Hashimoto's thyroiditis, but not in Graves' disease. The Journal of Clinical Endocrinology and Metabolism, 83, 4130-4139.

Behr, M. A., Wilson, M. A., Gill, W. P., Salamon, H., Schoolnik, G. K., Rane, S., \& Small, P. M. (1999). Vaccines by Whole-Genome DNA Microarray. Science, 284, 1520-1525.

Bellamy, R. (1998). Host susceptibility to tuberculosis. Doctoral dissertation, Oxford University, United Kingdom.

Bellamy, R., \& Hill, A. V. (1998a). Genetic susceptibility to mycobacteria and other infectious pathogens in humans. Current Opinion in Immunology, 10, 483-487.

Bellamy, R., Ruwende, C., Corrah, T., McAdam, K., \& Hill, A. (1998b). Variations in the NRAMP1 gene and susceptibility to tuberculosis in West Africans. New England Journal of Medicine, 338, 640-644.

Bellamy, R., Ruwende, T., Corrah, K., McAdam, M., Thursz, H., \& Hill, A. (1999). Tuberculosis and chronic hepatitis B virus infection in Africans and variation in the vitamin D receptor gene. Journal of Infectious Diseases, 179, 721-724.

Bidwell, L., Kee, L., Gallager, G., Kimberley, R., Huizinga, T., Mcdermott, M., Oksenberg, J., McNicholl, J., Pociot, F., Hardt, C., \& D’Alfonso, S. (1999). Cytokine gene polymorphism in human disease: On-line databases. Genes and Immunity, 1, 3-19.

Cervino, A. C., Lakiss, S., Sow, O., \& Hill, A. V. (2000). Allelic association between the NRAMP1 gene and susceptibility to tuberculosis in Guinea-Conakry. Annals of Human Genetics, 64, 507-512.
Clavreul, A., D’hellencourt, C. L., Montero-Menei, C., Potron, G., \& Couez, D. (1998). Vitamin D differentially regulates B7.1 and B7.2 expression on human peripheral blood monocytes. Immunology, 95, 272-277.

Deichmann, K., Bardutzky, J., Forster, J., Heinzmann, A., \& Kuehr, J. (1997). Common polymorphisms in the coding part of the IL4-receptor gene. Biochemical and Biophysical Research Communications, 231, 696-697.

Dolan, C. V., Molenaar, P. C., \& Boomsma, D. I. (1989). LISREL analysis of twin data with structured means. Behavior Genetics, 19, 51-62.

Donner, H., Braun, J., Seidl, C., Rau, H., Finke, R., Ventz, M., Walfish, P. G., Usadel, K. H., \& Badenhoop, K. (1997). Codon 17 polymorphism of the cytotoxic T lymphocyte antigen 4 gene in Hashimoto's thyroiditis and Addison's disease. The Journal of Clinical Endocrinology and Metabolism, 82, 4130-4132.

Eskdale, J., Gallagher, G., Verweij, C. L., Keijsers, V., Westendorp, R. G., \& Huizinga, T. W. (1998). Interleukin 10 secretion in relation to human IL-10 locus haplotypes. Proceedings of the National Academy of Sciences of the United States of America, 95, 9465-9470.

Fine, P. E. (1995). Variation in protection by BCG: Implications of and for heterologous immunity. Lancet, 346, 1339-1345.

Fulker, D. W., Cherny, S. S., Sham, P. C., \& Hewitt, J, K. (1999). Combined linkage and association sib-pair analysis for quantitative traits. American Journal of Human Genetics, 64, 259-267.

Gong, J., Zhang, M., Modlin, R. L., Linsley, P. S., Iyer, D., Lin, Y., \& Barnes, P. F. (1996). Interleukin 10 downregulates Mycobacterium tuberculosis induced Th1 responses and CTLA-4 expression. Infection and Immunity, 64, 913-918.

Gonzalez-Escribano, M. F., Rodriguez, R., Valenzuela, A., Garcia, A., Garcia-Lozano, J. R., \& Nunez-Roldan, A. (1999). CTLA4 polymorphisms in Spanish patients with rheumatoid arthritis. Tissue Antigens, 53, 296-300.

Greenfield, E. A., Nguyen, K. A., \& Kuchroo, V. K. (1998). CD28/B7 costimulation: A review. Critical Review in Immunology, 18, 389-418.

Haldane, J. B. (1949). Disease and evolution. La Ricerca Scientifica, 19(Suppl.), 68-76.

Heinzel, F. P., \& Maier, R. A., Jr. (1999). Interleukin-4independent acceleration of cutaneous leishmaniasis in susceptible $\mathrm{BALB} / \mathrm{c}$ mice following treatment with antiCTLA4 antibody. Infection and Immunity, 67, 6454-6460.

Hill, A. V. (1998). The immunogenetics of human infectious diseases. Annual Review of Immunology, 16, 593-617.

Jackett, P. S., Bothamley, G. H., Batra, H. V., Mistry, A., Young, D. B., \& Ivanyi, J. (1988). Specificity of anti- 
bodies to immunodominant mycobacterial antigens in pulmonary tuberculosis. Journal of Clinical Microbiology, 26, 2313-2318.

Jepson, A., Banya, W., Sisay-Joof, F., Hasan-King, M., Nunes, C., Bennett, S., \& Whittle, H. (1997). Quantification of the relative contribution of major histocompatibility complex (MHC) and non-MHC genes to human immune responses to foreign antigens. Infection and Immunity, 65, 872-876.

Jepson, A., Fowler, A., Banya, W., Singh, M., Bennett, S., Whittle, H., \& Hill, A. V. (2001). Genetic regulation of acquired immune responses to antigens of Mycobacterium tuberculosis: A study of twins in West Africa. Infection and Immunity, 69, 3989-3994.

Kaplan, G., \& Freedman, V. H. (1996). The role of cytokines in the immune response to tuberculosis. Research in Immunology, 147, 565-572.

Keane-Myers, A., Gause, W. C., Linsley, P. S., Chen, S. J., \& Wills-Karp, M. (1997). B7-CD28/CTLA-4 costimulatory pathways are required for the development of $\mathrm{T}$ helper cell 2-mediated allergic airway responses to inhaled antigens. Journal of Immunology, 158, 2042-2049.

Kirman, J., McCoy, K., Hook, S., Prout, M., Delahunt, B., Orme, I., Frank, A., \& Le Gros, G. (1999). CTLA-4 blockade enhances the immune response induced by mycobacterial infection but does not lead to increased protection. Infection and Immunity, 67, 3786-3792.

Koss, K., Satsangi, J., Fanning, G. C., Welsh, K.I., \& Jewell, D. P. (2000). Cytokine polymorphisms in inflammatory bowel diseases and normal controls: Differential effects on production and allele frequencies. Genes and Immunity, 1, 185-190.

Kristiansen, O. P., Larsen, Z. M., \& Pociot, F. (2000). CTLA-4 in autoimmune diseases: A general susceptibility gene to autoimmunity? Genes and Immunity, 1, 170-184.

Kubo, M., Yamashita, M., Abe, R., Tada, T., Okumura, K., Ransom, J., \& Nakayama, T. (1999). CD28 costimulation accelerates IL4 receptor sensitivity and IL4 mediated $\mathrm{T}_{\mathrm{H}} 2$ differentiation. Journal of Immunology, 163, 2432-2442.

Lischke, A., Moriggl, R., Brandlein, S., Berchtold, S., Kammer, W., Sebald, W., Groner, B., Liu, X., Hennighausen, L., \& Friedrich, K. (1998). The IL4 receptor activates STAT5 by a mechanism that relies upon common gamma-chain. Journal of Biological Chemistry, 273, 31222-31229.

Liu, Y., \& Janeway, C. A., Jr. (1991). Microbial induction of co-stimulatory activity for CD4 T-cell growth. International Immunology, 3, 323-332.

MacGregor, B., Pfitzner, J., Zhu, G,. Aitken, J. F., Green, A. C., \& Martin, N. G. (1999). Genetic and environmental contributions to size, color, shape and other characteristics of melanocytic naevi in a sample of adolescent twins. Genetic Epidemiology, 16, 40-53.
Martin, N. G., Clark, P., Ofulue, A. F., Eaves, L. J., Corey, L. A., \& Nance, W. E. (1987). Does the PI polymorphism alone control alpha-1-antitrypsin expression? American Journal of Human Genetics, 40, 267-277.

Mehra, V., Bloom, B. R., Bajardi, A. C., Grisso, C. L., Sieling, P. A., Alland, D., Convit, J., Fan, X. D., Hunter, S. W., \& Brennan, P. J. (1992). A major T cell antigen of Mycobacterium leprae is a $10-\mathrm{kD}$ heatshock cognate protein. Journal of Experimental Medicine, 175, 275-284.

Mitsuyasu, H., Yanagihara, Y., Mao, X. Q., Gao, P. S., Arinobu, Y., Ihara, K., Takabayashi, A., Hara, T., Enomoto, T., Sasaki, S., Kawai, M., Hamasaki, N., Shirakawa, T., Hopkin, J. M., \& Izuhara, K. (1999). Cutting edge: Dominant Effect of Ile50Val variant of the human IL-4 receptor alpha-chain in IgE synthesis. Journal of Immunology, 162, 1227-1231.

Mozo, L., Gayo, A., Suarez, A., Rivas, D., Zamorano, J., \& Gutierrez, C. (1998). Glucocorticoids inhibit IL4 and mitogen IL4 receptor alpha chain expression by different posttranscriptional mechanisms. The Journal of Allergy and Clinical Immunology, 102, 968-976.

Murray, C. J., Styblo, K., \& Rouillon, A. (1990). Tuberculosis in developing countries: Burden, intervention and cost. Bulletin of the International Union Against Tuberculosis and Lung Disease, 65, 6-24.

Murray, P. J., \& Young, R. A. (1999). Increased antimycobacterial immunity in IL10 deficient mice. Infection and Immunity, 67, 3087-3095.

Neale, M. C. (1997). Mx: Statistical modelling (4th ed.). Richmond, VA: Department of Psychiatry, Virginia Commonwealth University.

Neale, M. C., \& Cardon, L. (1992). Methodology for genetic studies of twins and families. Dordrecht, the Netherlands: Kluwer Academic.

Neale, M. C., Cherny, S. S., Sham, P. C., Whitfield, J. B., Heath, A. C., Birley, A. J., \& Martin, N. G. (1999). Distinguishing population stratification from genuine allelic effects with $\mathrm{Mx}$ : Association of $\mathrm{ADH} 2$ with alcohol consumption. Behavior Genetics, 29, 233-243.

Neale, M. C., \& Martin, N. G. (1989). The effects of age, sex and genotype on self-report drunkenness following a challenge dose of alcohol. Behavior Genetics, 19, 63-78.

O'Garra, A. (1998). Cytokines induce the development of functionally heterogeneous $\mathrm{T}$ helper cell subsets. Immunity, 8, 275-283.

Orme, I. M., Andersen, P., \& Boom, W. H. (1993). T-cell response to Mycobacterium tuberculosis. The Journal of Infectious Diseases, 167, 1481-1497.

Pearson, K. (1907). A first study of the statistics of pulmonary tuberculosis. London: Dulau.

Penna, G., \& Adorini, L. (2000). 1 Alpha, 25-dihydroxyvitamin D3 inhibits differentiation, maturation, activation, and survival of dendritic cells leading to 
impaired alloreactive $\mathrm{T}$ cell activation. Journal of Immunology, 164, 2405-2411.

Piemonti, L., Monti, P., Sironi, M., Fratecelli, P., Leone, B., Dal-Cin, E., Allavena, P., \& Di-Carlo, V. (2000). Vitamin D3 affects differentiation, maturation and function of human monocyte-derived dendritic cells. Journal of Immunology, 164, 4443- 4451.

Puffer, R. R. (1946). Familial susceptibility to tuberculosis. Its importance as a public health problem. Cambridge, MA: Harvard University Press.

Raviglione, M. C., Snider, D. E., Jr., \& Kochi, A. (1995). Global epidemiology of tuberculosis: Morbidity and mortality of a worldwide epidemic. Jama, 273, 220-226.

Reiser, H., \& Stadecker, M. J. (1996). Costimulatory B7 molecules in the pathogenesis of infectious and autoimmune diseases. The New England Journal of Medicine, 335, 1369-1377.

Rosenwasser, L. J., Klemm, D. J., Dresback, J. K., Inamura, H., Mascali, J. J., Klinnert, M., \& Borish, L. (1995). Promoter polymorphisms in the chromosome 5 gene cluster in asthma and atopy. Clinical and Experimental Allergy, 25(Suppl. 2), 74-78; discussion 95-96.

Rousset, F., Garcia, E., DeFrance, T., Peronne, C., Vezzio, N., Hsu, D. H., Kastelein, R., Moore, K. W., \& Banchereau, J. (1992). Interleukin 10 is potent growth and differentiation factor for activated human B lymphocytes. Proceedings of the National Academy of Sciences of the United States of America, 89, 1890-1893.

Saha, B., Chattopadhyay, S., Germond, R., Harlan, D. M., \& Perrin, P. J. (1998). CTLA4 (CD152) modulates the Th subset response and alters the course of experimental Leishmania major infection. European Journal of Immunology, 28, 4213-4220.

Schlesinger, L. S. (1993). Macrophage resistance of virulent but not attenuated strains of Mycobacterium tuberculosis is mediated by mannose receptors in addition to complement receptors. Journal of Immunology, 150, 2920-2930.

Schluger, N. W., Huberman, R., Holzman, R., Rom, W. N., \& Cohen, D. I. (1999). Screening for infection and disease as a tuberculosis control measure among indigents in New York City, 1994-1997. The International Journal of Tuberculosis and Lung Disease, 3, 281-286.

Schwartz, R. H. (1990). A cell culture model for T lymphocyte clonal anergy. Science, 248, 1349.

Seidl, C., Donner, H., Fischer, B., Usadel, K. H., Seifried, E., Kaltwasser, J. P., \& Badenhoop, K. (1998). CTLA4 codon 17 dimorphism in patients with rheumatoid arthritis. Tissue Antigens, 51, 62-66.

Sham, P. C., Cherny, S. S., Purcell, S., \& Hewiit, J. K. (2000). Power of linkage versus association analysis of quantitative traits, by use of variance-components models, for sibship data. American Journal of Human Genetics, 66, 1616-1630.
Surcel, H. M., Troye-Blomberg, M., Paulie, S., Andersson, G., Moreno, C., Pasvol, G., \& Ivanyi, J. (1994). Th1/Th2 profiles in tuberculosis, based on the proliferation and cytokine response of blood lymphocytes to mycobacterial antigens. Immunology, 81, 171-176.

Turner, D. M., Williams, D. M., Sankaran, D., Lazarus, M., Sinnott, P. J., \& Hutchinson, I. V. (1997). An investigation of polymorphism in the interleukin-10 gene promoter. European Journal of Immunogenetics, 24, 1-8.

Ueda, H., Howson, J. M., Esposito, L., Heward, J., Snook, H., Chamberlain, G., Rainbow, D. B., Hunter, K. M., Smith, A. N., Di Genova, G., Herr, M. H., Dahlman, I., Payne, F., Smyth, D., Lowe, C., Twells, R. C., Howlett, S., Healy, B., Nutland, S., Rance, H. E., Everett, V., Smink, L. J., Lam, A. C., Cordell, H. J., Walker, N. M., Bordin, C., Hulme, J., Motzo, C., Cucca, F., Hess, J. F., Metzker, M. L., Rogers, J., Gregory, S., Allahabadia, A., Nithiyananthan, R., Tuomilehto-Wolf, E., Tuomilehto, J., Bingley, P., Gillespie, K. M., Undlien, D. E., Ronningen, K. S., Guja, C., Ionescu-Tirgoviste, C., Savage, D. A., Maxwell, A. P., Carson, D. J., Patterson, C. C., Franklyn, J. A., Clayton, D. G., Peterson, L. B., Wicker, L. S., Todd, J. A., \& Gough, S. C. (2003). Association of the T-cell regulatory gene CTLA4 with susceptibility to autoimmune disease. Nature, 423, 506-511.

Walunas, T. L., Lenschow, D. J., Bakker, C. Y., Linsley, P. S., Freeman, G. J., Green, J. M., Thompson, C. B., \& Bluestone, J. A. (1994). CTLA-4 can function as a negative regulator of $\mathrm{T}$ cell activation. Immunity, 1 , 405-413.

Wandstrat, A., \& Wakeland, E. (2001). The genetics of complex autoimmune diseases: Non-MHC susceptibility genes. Nature and Immunology, 2, 802-809 (review).

Whitfield, J. B., Cullen, L. M., Jazwinska, E. C., Powell, L. W., Heath, A. C., Zhu, G., Duffy, D. L., \& Martin, N. G. (2000). Effects of HFEC282Y and H63D polymorphisms and polygenic background on iron stores in a large community sample of twins. American Journal of Human Genetics, 66, 1246-1258.

Wilkinson, R., Llewelyn, M., Toossi, Z., Patel, P., Pasvol, G., Lalvani, A., Wright, D., Latif, M., \& Davidson, R. (2000). Influence of vitamin D deficiency and vitamin $\mathrm{D}$ receptor polymorphisms on tuberculosis among Gujarati Asians in west London: A case control study. Lancet, 355, 618-621.

Yanagawa, T., Taniyama, M., Enomoto, S., Gomi, K., Maruyama, H., Ban, Y., \& Saruta, T. (1997). CTLA4 gene polymorphism confers susceptibility to Graves' disease in Japanese. Thyroid, 7, 843-846.

Young, D. B., Kent, L., \& Young, R. A. (1987). Screening of a recombinant mycobacterial DNA library with polyclonal antiserum and molecular weight analysis of expressed antigens. Infection and Immunity, 55, 1421-1425. 